\title{
Polypharmacy: Misleading, but manageable
}

\author{
Reamer L Bushardt ${ }^{\prime}$ \\ Emily B Massey' \\ Temple W Simpson' \\ Jane C Ariail ${ }^{2}$ \\ Kit N Simpson ${ }^{3}$ \\ 'Department of Clinical Services, \\ ${ }^{2}$ Center for Academic Excellence, \\ Medical University of South Carolina, \\ Charleston, South Carolina, USA; \\ ${ }^{3}$ Department of Health Administration \\ and Policy, Medical University of \\ South Carolina, Charleston, South \\ Carolina, USA
}

\begin{abstract}
The percentage of the population described as elderly is growing, and a higher prevalence of multiple, chronic disease states must be managed concurrently. Healthcare practitioners must appropriately use medication for multiple diseases and avoid risks often associated with multiple medication use such as adverse effects, drug/drug interactions, drug/disease interactions, and inappropriate dosing. The purpose of this study is to identify a consensus definition for polypharmacy and evaluate its prevalence among elderly outpatients. The authors also sought to identify or develop a clinical tool which would assist healthcare practitioners guard against inappropriate drug therapy in elderly patients. The most commonly cited definition was a medication not matching a diagnosis. Inappropriate was part of definitions used frequently. Some definitions placed a numeric value on concurrent medications. Two common definitions (ie, 6 or more medications or a potentially inappropriate medication) were used to evaluate polypharmacy in elderly South Carolinians $(n=1027)$. Data analysis demonstrates that a significant percentage of this population is prescribed six or more concomitant drugs and/or uses a potentially inappropriate medication. The findings are $29.4 \%$ are prescribed 6 or more concurrent drugs, $15.7 \%$ are prescribed one or more potentially inappropriate drugs, and 9.3\% meet both definitions of polypharmacy used in this study. The authors recommend use of less ambiguous terminology such as hyperpharmacotherapy or multiple medication use. A structured approach to identify and manage inappropriate polypharmacy is suggested and a clinical tool is provided.
\end{abstract}

Keywords: hyperpharmacotherapy, polypharmacy, geriatrics, inappropriate medication, inappropriate pharmacy, multiple medication use

\section{Background}

The use of multiple medications, often termed polypharmacy, is recognized as an increasingly serious problem in the current healthcare system. The US General Accounting Office reports significant morbidity and mortality associated with inappropriate polypharmacy. In addition, polypharmacy is recognized as an expensive practice: the US Center for Medicare and Medicaid Services estimates that polypharmacy costs its nation's health plans more than US\$50 billion annually (Berenbeim 2002). But the issue of multiple medication use, particularly by elderly patients, is a complex one. The potential risks of polypharmacy are evident; however, so are the benefits to patients when medication therapies are combined to cure, slow the progression, or reduce the symptoms of disease. Additionally, a plethora of drug therapies for chronic disease can improve quality of life and prevent complications, including disability and unnecessary hospitalization. Balancing the risks and benefits of multiple drug therapies in older adults becomes a challenging endeavor for prescribers. Education and strategies which enable the healthcare practitioner to achieve successful polypharmacy and avoid inappropriate polypharmacy must be developed and shared.

Patients 65-years-old and older are the largest consumers of prescription and nonprescription medications in the US, and the use of prescription and nonprescription medications among this group has more than doubled since 1990 and continues 
to rise, according to the Centers for Disease Control and Prevention (CDC). Elderly Americans consume one-third of all the prescription medications prescribed each year, yet they comprise less than $13 \%$ of the population (Azad 2005; CDC 2005). The relatively high rates of drug consumption by elderly patients and numerous other factors contribute to the increased prevalence of medication-associated morbidity and mortality affecting this population. Significant contributing factors are the physiologic changes associated with aging, which may include decreased renal elimination, decreased hepatic function, decreased total body water and lean body mass, and age-related declines in vision and hearing. Several of these changes can lead to alterations in the pharmacokinetics of medications for many elderly patients, namely altered distribution, metabolism, and elimination. Other contributing factors are pathophysiologic alterations involved with disease, frequency of chronic disease and medical comorbidities, communication barriers, and healthcare delivery involving multiple prescribers (GAO 2000; Delafuente 2003).

\section{Purpose}

Because individuals are living longer and accruing chronic diseases, practitioners have a new responsibility to prescribe appropriately the many medications available to manage concurrent disease states. The plethora of pharmaceutical options must be balanced with the potential risk of multiple medication use. These risks include, but are not limited to, adverse effects, drug/drug interactions, drug/disease interactions and inappropriate dosing regimens. Primary care health professionals such as physicians, physician assistants, and nurses have an enormous opportunity to survey patients for this risk given their accessibility and roles in the coordination of care. Nearly $45 \%$ of physician assistants, for example, practice in family medicine, general internal medicine, or internal medicine subspecialties, according to the American Academy of Physician Assistants Census Report (AAPA 2006). These providers and others have an opportunity to ensure appropriate medication management, especially in their elderly patients. Originally, the purpose of this study was to identify the consensus definition for polypharmacy and evaluate its prevalence within elderly outpatients in the state of South Carolina. A review of the literature, however, revealed that no consensus existed in the medical literature on the definition for polypharmacy. Thus, it became necessary to evaluate and clarify terminology currently used in the medical literature to describe multiple medication use in the older adult before evaluating the prevalence of polypharmacy. Additionally, the authors sought to identify or develop a clinical tool to assist healthcare practitioners guard against inappropriate drug therapy in elderly patients.

\section{Methods}

In the first phase of this study, a literature review was conducted within OVID for original articles published between January 1997 and May 2007, using the following search terms and phrases: 'polypharmacy,' 'elderly,' 'geriatrics,' 'inappropriate medication,' and 'multiple medication use.' English language articles available in local holding which described 'polypharmacy' or the issue of the simultaneous use of multiple medications in elderly patients were evaluated. Discrete definitions of polypharmacy were identified and recorded.

Throughout the literature, numerous articles used the term 'polypharmacy' and the phrase 'inappropriate drug use' interchangeably. The research reported that methods most often used for identifying inappropriate drug use involved the use of criteria, primarily the criteria developed, and more recently revised, by Beers and colleagues (Beers 1997; Fick et al 2003). The investigators adapted a list of inappropriate drugs from two primary sources for use in this study (Fick et al 2003; Bressler and Bahl 2003). The medications used in this research were based upon the Beers' criteria but were limited to those identified as "high risk" (see Table 2). This list is labeled as 'potentially inappropriate,' because we recognize that use of one or more of these agents in an older adult could be justified by specific circumstances, for example, if safer alternatives had been exhausted.

Two different definitions of polypharmacy were applied to the database, which consisted of outpatient medical record data randomly collected by physician assistant students at the time of patient encounters during supervised clinical training from August 2006 to May 2007. Polypharmacy was defined as either "use of at least one potentially inappropriate drug" (see Table 2) or "the presence of six or more concurrent medications". The database included patient demographics (ie, age, gender, ethnicity, educational level, and marital status), vital signs, diagnoses, prescription medications, health-related quality of life, and disease-specific markers when applicable (ie, blood pressure, urine microalbumin, hemoglobin A1c, creatinine clearance, liver transaminases, estimated left ventricular ejection fraction, and others). These outpatient data were collected from more than 500 outpatient clinical sites throughout the state of South Carolina representing the following disciplines: family medicine, general internal medicine, pediatrics, general surgery, gynecology and obstetrics, emergency medicine, and internal medicine 
subspecialties. At the time of analysis the database contained 10,455 discrete patient entries, and the 1270 entries involving patients 65 -years or older were selected for investigation.

\section{Results}

The term 'polypharmacy' is frequently used in the medical literature; however, the definitions of polypharmacy often varied from scholar to scholar. No consensus definition for polypharmacy was readily identified. The various definitions of polypharmacy identified in 11 publications reviewed are summarized in Table 1. The most commonly cited definition, which appeared in four articles, "was medication did not match diagnosis". The term 'inappropriate' was part of definitions used in six articles. Several other different definitions, used by at least three scholars, involved one of the following concepts: many medications, duplication of

Table I Definitions of polypharmacy

\begin{tabular}{|c|c|c|c|}
\hline $\begin{array}{l}\text { Specific definitions of polypharmacy } \\
\text { (Polypharmacy is...) }\end{array}$ & $\begin{array}{l}\text { Number } \\
\text { of articles }\end{array}$ & $\begin{array}{l}\text { Other descriptions of inappropriate } \\
\text { medication use }\end{array}$ & $\begin{array}{l}\text { Number } \\
\text { of articles }\end{array}$ \\
\hline Medication does not match the diagnosis* & $4^{5,9,16,22}$ & Drug/drug interactions & $3^{2,10,22}$ \\
\hline Many medications & $3^{10,14,22}$ & Excessive duration & $3^{2,10,22}$ \\
\hline Duplication of medication* & $3^{5,9,16}$ & $\begin{array}{l}\text { Inappropriate drugs (ie, lack of proven benefit, } \\
\text { drug indication, etc.) }\end{array}$ & $2^{2,10}$ \\
\hline Drug/drug interactions* & $2^{9,16}$ & Drugs that cause adverse effects & $2^{10,22}$ \\
\hline $\begin{array}{l}\text { Inappropriate dosing frequency (excessive, too low, } \\
\text { too long)* }\end{array}$ & $2^{5,16}$ & Drug/disease interactions & $2^{2,22}$ \\
\hline $\begin{array}{l}\text { Medication prescribed to treat the side effect } \\
\text { of another medication (except for cases where there } \\
\text { is no other option)* }\end{array}$ & $2^{5,16}$ & $\begin{array}{l}\text { Availability of an equally effective, lower-cost } \\
\text { alternative }\end{array}$ & $2^{2,22}$ \\
\hline Two or more drugs of the same chemical class & $I^{8}$ & Excessive dosages & $2^{2,10}$ \\
\hline Two or more meds to treat the same condition & $1^{8}$ & $\begin{array}{l}\text { Inappropriate dosing frequency } \\
\text { (excessive, too low, too long) }\end{array}$ & $2^{2,10}$ \\
\hline $\begin{array}{l}\text { Two or more agents with the same or similar } \\
\text { pharmacologic actions to treat different conditions }\end{array}$ & $1^{8}$ & Complicated drug regimen affecting compliance & $2^{2,10}$ \\
\hline $\begin{array}{l}\text { Minor polypharmacy }=2-4 \text { meds. Major } \\
\text { polypharmacy } \geq 5 \text { meds. }\end{array}$ & $1^{20}$ & $\begin{array}{l}\text { Prescription of multiple meds by different specialists } \\
\text { for treating concurrent conditions }\end{array}$ & $I^{2}$ \\
\hline 3,5 , or 6 different medications & 17 & Medication does not match the diagnosis & $1^{22}$ \\
\hline Two or more medications & $1^{18}$ & $\begin{array}{l}\text { Medication prescribed to treat the side effect } \\
\text { of another medication (except for cases where } \\
\text { there is no other option) }\end{array}$ & $1^{22}$ \\
\hline Greater than 5 medications & $1^{5}$ & Polypills & 122 \\
\hline Excessive use of medication & $1^{16}$ & More than one pharmacy used & $1^{22}$ \\
\hline Unnecessary use of medication & $1^{16}$ & Multiple prescribers of medication & $1^{22}$ \\
\hline Medications prescribed greater than twice per day & $I^{5}$ & High risk medications & 122 \\
\hline Complicated drug regimen effecting compliance* & $1^{9}$ & Number of medications & $1^{22}$ \\
\hline Contraindicated in the elderly & $1^{9}$ & Diet & $1^{22}$ \\
\hline $\begin{array}{l}\text { Taking an OTC medication, an herbal product or } \\
\text { another person's medication }\end{array}$ & $1^{9}$ & Frequency of medication therapy monitoring & $1^{22}$ \\
\hline $\begin{array}{l}\text { Availability of an equally effective, lower-cost } \\
\text { alternative* }\end{array}$ & $1^{5}$ & Male Gender & $1^{22}$ \\
\hline $\begin{array}{l}\text { Patient misunderstanding of the use of the } \\
\text { medication (purpose, how to take it, side effects } \\
\text { possible, toxicity signs, etc) }\end{array}$ & $1^{5}$ & New resident to nursing home & $1^{22}$ \\
\hline Dosage does not reflect age/renal/liver status & $1^{5}$ & Medication is not the most effective available & $1^{22}$ \\
\hline Improvement after discontinuation of medications & $1^{16}$ & Treatment goals unmet & $I^{2}$ \\
\hline Diagnosis no longer present & $I^{5}$ & Duplication of medication & $I^{2}$ \\
\hline
\end{tabular}

*Also a description of multiple medication use. 
Table 2 Percentage of patients prescribed potentially inappropriate drugs

\begin{tabular}{ll}
\hline Generic name & Patients prescribed \\
& each medicine (\%) \\
\hline Alprazolam & 11.56 \\
Lorazepam & 11.1 \\
Amitriptyline & 9.1 \\
Nifedipine & 8.5 \\
Promethazine & 6.0 \\
Oxybutynin & 6.5 \\
Fluoxetine & 5.0 \\
Oxybutynin & 4.5 \\
Cyclobenzaprine & 4.0 \\
Temazepam & 3.5 \\
Indomethacin & 3.5 \\
Amiodarone & 3.5 \\
Hydroxyzine & 3.0 \\
Diphenhydramine & 3.0 \\
Metaxalone & 3.0 \\
Naproxen & 2.5 \\
Chlorazepate & 2.0 \\
Diazepam & 2.0 \\
Ketorolac & 1.5 \\
Belladonna alkaloids & 1.0 \\
Perpheazine - amitriptyline & 1.0 \\
Piroxicam & 1.0 \\
Clidinium - Chlordiazepoxide & 1.0 \\
Chlorpheniramine & 1.0 \\
Oxaprozin & 1.0 \\
Meperidine & 1.0 \\
Chlordiazepoxide - amitriptyline & 0.5 \\
Chlordiazepoxide - amitriptyline & 0.5 \\
Diyclomine & 0.5 \\
Hyoscyamine & 0.5 \\
Nitrofurantoin & 0.5 \\
Oxazepam & 0.5 \\
Doxepin & 0.5 \\
\hline Nots: Ove & \\
\hline
\end{tabular}

Notes: Over the counter medications are not included; Barbiturates are not included as there is no knowledge whether or not the patient is taking them to control seizures.

medications, drug/drug interactions, and excessive duration. Some definitions for polypharmacy place a value on the number of concurrent medications; the most commonly referenced number was six medications or more. This finding is interesting especially because elderly residents of extended care facilities typically receive more than seven medications per day (Chutka et al 2004).

Because no consensus definition for polypharmacy emerged during our literature review, we applied two of the most commonly cited ones to our dataset, specifically "use of a potentially inappropriate drug" or "use of six or more concomitant drugs". The analyses of the data collected from elderly patients demonstrate that a significant percentage of this population are, in fact, prescribed six or more concomitant drugs and/or use a potentially inappropriate medication. Of the 1270 elderly patients evaluated, 29.4\% are prescribed 6 or more concurrent drugs, $15.7 \%$, or 199 patients, are prescribed one or more potentially inappropriate drugs, and 9.3\% meet both definitions of polypharmacy used in this study (ie, "six or more concurrent medications" and "at least one potentially inappropriate drug"). The potentially inappropriate medications prescribed include medications known to produce significant central nervous system depressant or anti-cholinergic effects. For example, $32 \%$ of the patients who were prescribed a potentially inappropriate drug received at least one benzodiazepine-containing products (see Table 2).

\section{Discussion}

Poly, of Greek origin, is simply defined by Webster as "many, several, much, multi, containing an indefinite number." Attaching this prefix to the word 'pharmacy' implies many pharmacies, and is devoid of any moral value. The results presented in Table 1 clearly demonstrate the lack of consistency with the use of the term 'polypharmacy' in the medical literature. To further complicate the issue, the term 'polypharmacy' connotes a negative, inappropriate medication use in some areas of the literature, but in other publications, the term describes an appropriate combination of multiple medications. In other words, one word, polypharmacy, can be both negative and positive. This duality makes objective research difficult, to say the least. Of the 11 articles that describe polypharmacy, 24 distinctly different definitions emerge. The most common definition identified, "medication does not meet diagnosis," is clearly synonymous with unnecessary or inappropriate. Many of the definitions identified were also quite vague, complicating any attempt to quantify or study further the issue through standardized, measureable methodologies. For example, the description, "excessive use," can be interpreted in many ways. Excessive might refer to the frequency of the drug, the dosage, unintentional overuse, intentional misuse or abuse, or drug consumption when a nondrug alternative is more appropriate. The lack of objective terminology and precision in definition is replicated in the multiple interpretations of the descriptions, "many medications," "unnecessary use," and "duplication of medication". Arguably, prescribing a single medication that does not match a diagnosis would be considered inappropriate polypharmacy. A quantity-specific definition of polypharmacy, however, is easy to construct and apply, but this method is associated with a relatively high rate of false positives, not specific for 'inappropriate medication use.' The vague and often dissimilar use of the term 'polypharmacy' within the literature supports the discontinuation of its use. 
To illustrate the complexity of evaluating the prevalence of polypharmacy among older adults, we calculated the prevalence using two commonly cited definitions for polypharmacy to determine their validity and reliability. We found $13.7 \%$ more patients were identified as recipients of 'potentially inappropriate polypharmacy' when the quantity-specific definition was used, 'six or more concurrent medications.' When a drug-specific definition was applied, we found that $15.7 \%$ were recipients of 'potentially inappropriate polypharmacy.' These disparate results call the validity and reliability into question. If our population is reflective of our country's geriatric population, this variance could represent approximately 4.9 million patients based on data from the US Consensus Bureau (US Department of Commerce 2004).

According to several sources, including the American Psychiatric Association, the use of potentially inappropriate drugs such as benzodiazepines is commonly associated with intellectual and cognitive impairment, psychomotor impairment, and increased risk for fall or motor vehicle accident (Bugonvic and Greenfield 2004). Differentiating age-related, disease-related, and drug-related impairment can be challenging for any provider. A targeted approach to identify potentially inappropriate medications such as screening for particular high-risk drugs or contraindicated drugs may provide a higher sensitivity. Further evaluation to validate and identify the relative sensitivity of the definitions applied to the database in this pilot project is needed. This effort will require more intensive review of individual patient profiles to identify contraindicated drugs, significant drug/drug interactions, major drug/disease interactions, apparent drug associated morbidity or mortality, and unwarranted duplications of therapy. If validated, one or both of these definitions could then be applied to claims data or managed-care patient populations for comparison. Additionally, three unanswered questions emerged during our research that require additional discussion and exploration: Does pharmacy refer to medications or the actual location where clients pick up prescriptions? Is 'polypharmacy' a positive term meaning that multiple medications are used to treat disease effectively? Is it a negative term denoting inappropriate drug therapy? Or is it a neutral term simply referring to the concomitant use of more than one medications? Are the terms 'polypharmacy' and the phrase 'inappropriate drug use' mutually exclusive?

Our research supports the discontinuation of the use of the term 'polypharmacy,' agreeing with Preskorn and colleagues (2005) as well as Bushardt and Jones (2005). Preskorn (2005) recommends the alternative phrase 'multiple medication use.' However, Preskorn's phrase has a neutral connotation because concomitant use of multiple drugs is often supported by evidence-based guidelines for various disease states (Preskorn 2005). Examples include treatment guidelines for heart failure developed by the American College of Cardiology and the American Heart Association as well as treatment guidelines for hypertension published in the seventh report of the Joint National Commission on Prevention, Detection, Evaluation and Treatment of High Blood Pressure (Chobanian et al 2003). Bushardt and Jones (2005) propose the alternative term 'hyperpharmacotherapy' because it offers a different connotation. According to the American Heritage Dictionary, 'pharmacotherapy' refers to the treatment of disease with the use of drugs. Thus, the addition of the prefix 'hyper-' to 'pharmacotherapy' implies an excessive use of drugs for treatment of disease.

\section{Implications for practice}

Because the elderly population has a higher prevalence of chronic diseases, multiple drug use is very common (Jorgensen et al 2001). An increase in the number of medications may pose a higher risk of hyperpharmacotherapy, and an assessment tool to ensure the safety of patients taking multiple drugs is needed (Feinberg and Simonson 2005). Many prescribers may feel overwhelmed when encountering an older adult who has been prescribed multiple drugs or whose drug therapy regimen is quite complex. The process for reviewing an individual patient's drug therapy regimen for inappropriate polypharmacy, or 'hyperpharmacotherapy,' can be taught and supported by various clinical tools. Corrective actions to reduce the burden of hyperpharmacotherapy for a patient may require a considerable amount of time

Table 3 Hyperpharmacotherapy resource guides

\begin{tabular}{|c|c|c|c|}
\hline Resource title & Author & Website & Journal \\
\hline $\begin{array}{l}\text { I. The } 9 \text { key questions to address } \\
\text { polypharmacy in the elderly }\end{array}$ & Bushardt and Jones & $\begin{array}{l}\text { http://jaapa.com/issues/j2005050I/articles/ } \\
\text { polypharm0505.htm }\end{array}$ & JAAPA May 2005 \\
\hline 2. Beer's criteria & Beers et al & $\begin{array}{l}\text { http://archinte.ama-assn.org/cgi/content/ } \\
\text { full//63/22/27/6 }\end{array}$ & $\begin{array}{l}\text { Archives of Internal Medicine } \\
\text { December } 2003\end{array}$ \\
\hline $\begin{array}{l}\text { 3. Principles of drug therapy for the elderly } \\
\text { patient }\end{array}$ & Bressler and Bahl & $\begin{array}{l}\text { http://www.mayoclinicproceedings.com/ } \\
\text { inside.asp?AID=76/\&UID= }\end{array}$ & Mayo Clinic Proceedings 2003 \\
\hline
\end{tabular}


and close monitoring as some drugs require tapering and monitoring. Additionally, pitfalls may be encountered if a provider attempts to make multiple changes to a regimen at a single point in time. Zarowitz (2006) has previously discussed the potential challenges involved with careless discontinuation of medications, including disease exacerbation and hospitalization. Therefore, a more rational approach to drug discontinuation might involve tapering a single drug therapy at a time with careful monitoring for symptoms of withdrawal and disease exacerbation. Because the purpose of eliminating inappropriate polypharmacy includes enhancing quality of life for patients, it is important to pay careful attention to the discontinuation process.
Feinberg and Simonson (2005) suggest a comprehensive review of a patient's drug regimen be performed annually, or more frequently if indicated. Several clinical tools have been published to help providers reduce hyperpharmacotherapy. Bushardt and Jones (2005) previously developed and published a series of nine questions for physician assistants to use to guide the drug therapy evaluation process (see Table 3). We have developed a comprehensive tool called the Hyperpharmacotherapy Assessment Tool (HAT), adapted from Bergman-Evans' Medication Management Outcome Monitor (2006). It appears in Figure 1. Modifications were made to create a more concise tool as well as to include pertinent components not listed in the form developed by

\section{Hyperpharmacotherapy Assessment Tool (HAT)}

Patient Name:

Instructions: Evaluate drug profile by using criteria below. The first two criteria require numbers. Otherwise, use $Y=Y e s, N=$ No. When question is answered "Yes," investigate ways to improve medication regimen. Drug discontinuation or tapering should generally be engaged with a single drug at the time. When choosing among multiple medications well suited for discontinuation, consider the underlying problem and review this series in descending order of priority: safety, tolerability, efficacy, tolerability, price, and simplicity of use.

\begin{tabular}{|c|c|c|c|c|c|c|}
\hline & $\begin{array}{l}\text { Visit I } \\
\text { Date: }\end{array}$ & $\begin{array}{l}\text { Visit } 2 \\
\text { Date: }\end{array}$ & $\begin{array}{l}\text { Visit } 3 \\
\text { Date: }\end{array}$ & $\begin{array}{l}\text { Visit } 4 \\
\text { Date: }\end{array}$ & $\begin{array}{l}\text { Visit } 5 \\
\text { Date: }\end{array}$ & $\begin{array}{l}\text { Visit } 6 \\
\text { Date: }\end{array}$ \\
\hline \multicolumn{7}{|c|}{ GOAL I: Monitor Number of Medications } \\
\hline \multicolumn{7}{|l|}{$\begin{array}{l}\text { Total \# of Prescription medications, OTC medications, vitamins or minerals, } \\
\text { dietary supplements and herbs }\end{array}$} \\
\hline \multicolumn{7}{|l|}{ Total \# of Meds systemically or gastrointestinally absorbed } \\
\hline \multicolumn{7}{|c|}{ GOAL II: Decrease Inappropriate Drug Use } \\
\hline \multicolumn{7}{|l|}{ Has the disease state resolved that the drug(s) was originally prescribed for? } \\
\hline \multicolumn{7}{|l|}{ Is non-drug therapy an option? } \\
\hline \multicolumn{7}{|l|}{ Is there another drug more effective for the disease? } \\
\hline \multicolumn{7}{|l|}{ Is there an equally effective, lower-cost drug available? } \\
\hline \multicolumn{7}{|l|}{ Is the patient taking another person's medication? } \\
\hline \multicolumn{7}{|l|}{ Is the drug inappropriate for use in the elderly? } \\
\hline \multicolumn{7}{|l|}{ Are treatment goals unachieved? } \\
\hline \multicolumn{7}{|c|}{ GOAL III: Decrease Inappropriate Pharmacology } \\
\hline \multicolumn{7}{|l|}{ Are there any adverse effects to the medication(s)? } \\
\hline \multicolumn{7}{|l|}{$\begin{array}{l}\text { Is the patient using } 2 \text { or more drugs of the same chemical class or } \\
\text { pharmacologic action? }\end{array}$} \\
\hline \multicolumn{7}{|l|}{$\begin{array}{l}\text { Is the patient taking combination pill(s) in which one of the medications is } \\
\text { inappropriate? }\end{array}$} \\
\hline \multicolumn{7}{|l|}{$\begin{array}{l}\text { Are there any drug-drug interactions? (OTC, herbal supplements, prescrip- } \\
\text { tion meds) }\end{array}$} \\
\hline \multicolumn{7}{|l|}{ Are there any adverse drug-disease interactions? } \\
\hline \multicolumn{7}{|l|}{ Does the patient's diet interfere with pharmacologic action? } \\
\hline \multicolumn{7}{|l|}{ Is there risk of addiction from the medication? } \\
\hline \multicolumn{7}{|l|}{ Is the patient at risk for accumulation from long-term use? } \\
\hline \multicolumn{7}{|c|}{ GOAL IV: Optimize dosing regimen } \\
\hline \multicolumn{7}{|l|}{ Is there a lower effective dose of the medication? } \\
\hline Does the patient have any medications dosed more than 2 times per day? & & & & & & \\
\hline
\end{tabular}




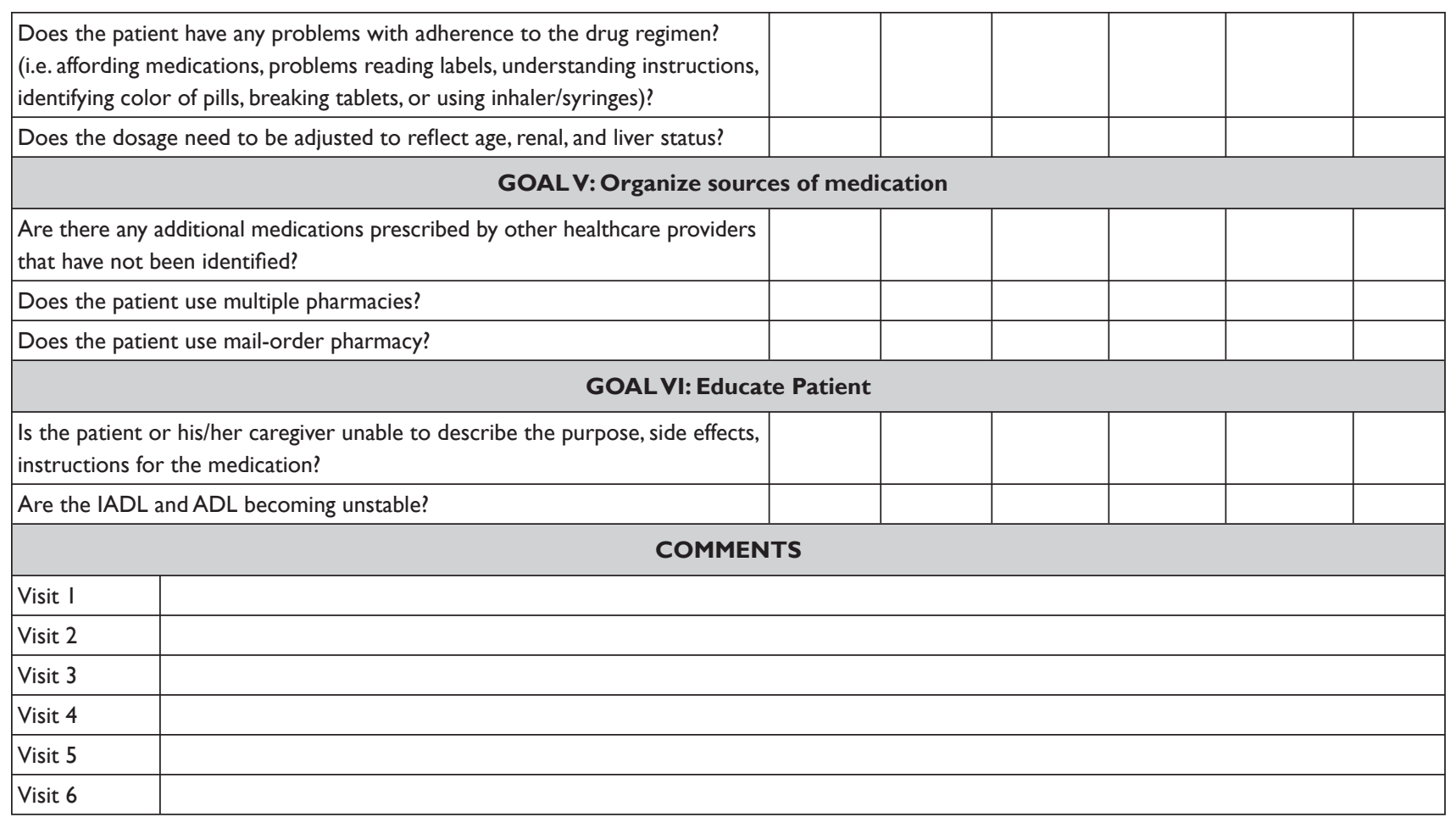

Figure I Hyperpharmacotherapy assessment tool (Adapted with permission from Bergman-Evans B. 2006 Evidence-based guideline: Improving medication management for older adult clients.J Gerontol Nurs, 32:6-14).

Bergman-Evans. Additional research by physician assistants can further refine this instrument.

Health professionals, particularly those in primary care, are well positioned to impact appropriate use of medication therapies for older adults. Mid-level practitioners such as physician assistants may be able to justify spending more time with patients in today's healthcare system versus their physician supervisors. Additional time during a clinical interview could be used to conduct the medication review process.

\section{References}

Acello B. 2003. Following the guideline for pain control in the elderly. Nursing, 33:17.

Allardx J, et al. 2001. Efficacy of a clinical medication review on the number of potentially inappropriate prescriptions prescribed for communitydwelling elderly people. Can Med Assoc J, 164:1291-6.

[AAPA] American Academy of Physician Assistants. 2006. 2006 AAPA Physician Assistant Census Report [online]. Accessed March 20, 2007. URL: http://www.aapa.org/research/06census-content.html.

Beers MH. 1997. Explicit criteria for determining potentially inappropriate medication use by the elderly. Arch Intern Med, 157:1531-6.

Bergman-Evans B. 2006 Evidence-based guideline: Improving medication management for older adult clients. J Gerontol Nurs, 32:6-14.

Bressler R, Bahl JJ. 2003. Principles of drug therapy for the elderly patient. Mayo Clin Proc, 78:1564-77.

Bogunovic OJ, Greenfield SF. 2004. Practical geriatrics: Use of benzodiazepines among elderly patients. Psychiatr Serv, 55:233-5.

Brager R, Sloand E. 2005. The spectrum of polypharmacy. Nurs Pract, 30:44-50.

Bushardt RL, Jones KW. 2005. Nine key questions to address polypharmacy in the elderly. JAAAPA, 18:32-7.
Chobanian AV, Bakris GL, Black HR, et al; and the National High Blood Pressure Education Program Coordinating Committee. 2003. The Seventh Report of the Joint National Committee on Prevention, Detection, Evaluation, and Treatment of High Blood Pressure: The JNC 7 Report. JAMA, 289:doi:10.1001/jama.289.19.2560.

Chutka DS, Takahashi PY, Hoel RW. 2004. Inappropriate medications for elderly patients. Mayo Clin Proc, 79:122-39.

Dimant J. 2003. Roles and responsibilities of attending physicians in skilled nursing facilities. $J$ Am Med Dir Assoc, 4:231-43.

Feinberg JL, Simonson W. 2005 Medication-related problems in the elderly: Defining the issues and identifying solutions. Drugs Aging, 22:559-69.

Fick DM, Cooper JW, Wade WE, et al. 2003. Updating the Beers criteria for potentially inappropriate medication use in older adults. Arch Intern Med, 163:2716-24.

Frank C. 2002. Conscientious family physicians and polypharmacy. Can Fam Phys, 48:1418-20.

Howard M, Dolovich L, Kaczorowski J, et al. 2004. Prescribing of potentially inappropriate medications to elderly people. Fam Pract, 21:244-7.

Jones BA. 1997. Decreasing polypharmacy in clients most at risk. $A A C N$ Clinical Issues, 8:627-34.

Jorgensen T, Johansson S, Kennerfalk A, et al. 2001. Prescription drug use, diagnoses and healthcare utilization among the elderly. Ann Pharmacother, 35:1004-9.

Nusbaum NJ. 2005. Improving elder care by integrating geriatric expertise into medicare. Drugs Aging, 22:371-4.

Preskorn SH. 2005. Multiple medication use in patients seen in the Veterans Affairs healthcare system: So what? J Psychiatr Pract, 11:46-9.

Preskorn SH, Silkey B, Shah R, et al. 2005. Complexity of Medication Use in the Veterans Affairs Healthcare System: Part I: Outpatient Use in Relation to Age and Number of Prescribers. J Psychiatr Pract, 11:5-14.

US Department of Commerce. 2004. US Census Bureau News: Census Bureau estimates number of adults, older people and school-aged children in states [online]. Accessed March 20, 2007. URL: http://www.census. gov/Press-Release/www/releases/archives/population/001703.html.

Zarowitz, Barbara J. (2006). Medication overuse and misuse. Geriatr Nurs, $27: 204-5$. 
